\title{
Numerical Analysis on the Storage of Nuclear Waste in Gas- Saturated Deep Coal Seam
}

\author{
Teng Teng $\mathbb{D}^{1,2,3}$ Yuming Wang, ${ }^{1}$ Xiaoyan Zhu, ${ }^{1}$ Xiangyang Zhang $\mathbb{D}^{2},{ }^{2}$ Sihai $Y i,{ }^{3,4}$ \\ Guowei Fan, ${ }^{1}$ and Bin Liu $^{2}$ \\ ${ }^{1}$ Beijing Key Laboratory for Precise Mining of Intergrown Energy and Resources, China University of Mining and Technology-Beijing, \\ Beijing 100083, China \\ ${ }^{2}$ Key Laboratory of Safety and High-Efficiency Coal Mining, Ministry of Education (Anhui University of Science and Technology), \\ Huainan 232001, China \\ ${ }^{3}$ State Key Laboratory of Water Resource Protection and Utilization in Coal Mining, Beijing 100011, China \\ ${ }^{4}$ School of Safety Engineering, North China Institute of Science and Technology, Langfang 065201, China
}

Correspondence should be addressed to Teng Teng; t.teng@cumtb.edu.cn and Xiangyang Zhang; xyzhang@aust.edu.cn

Received 23 April 2021; Accepted 23 June 2021; Published 12 July 2021

Academic Editor: Jia Liu

Copyright (c) 2021 Teng Teng et al. This is an open access article distributed under the Creative Commons Attribution License, which permits unrestricted use, distribution, and reproduction in any medium, provided the original work is properly cited.

\begin{abstract}
Nuclear power has contributed humanity a lot since its successful usage in electricity power generation. According to the global statistics, nuclear power accounts for $16 \%$ of the total electricity generation in 2020 . However, the rapid development of nuclear power also brings up some problems, in which the storage of nuclear waste is the thorny one. This work carries out a series of modeling and simulation analysis on the geological storage of nuclear waste in a gas-saturated deep coal seam. As the first step, a coupled heat-solid-gas model with three constitutional fields of heat transfer, coal deformation, and gas seepage that based on three governing conservation equations is proposed. The approved mechanical model covers series of interactive influences among temperature change, dual permeability of coal, thermal stress, and gas sorption. As the second step, a finite element numerical model and numerical simulation are developed to analyze the storage of nuclear waste in a gas-saturated deep coal seam based on the partial differential equations (PDE) solver of COMSOL Multiphysics with MATLAB. The numerical simulation is implemented and solved then to draw the following conclusions as the nuclear waste chamber heats up the surrounding coal seam firstly in the initial storage stage of 400 years and then be heated by the far-field reservoir. The initial velocity of gas flow decreases gradually with the increment of distance from the storage chamber. Coal gas flows outward from the central storage chamber to the outer area in the first 100 years when the gas pressure in the region nearby the central storage chamber is higher than that in the far region and flows back then while the temperature in the outer region is higher. The modeling and simulation studies are expected to provide a deep understanding on the geological storage of nuclear waste.
\end{abstract}

\section{Introduction}

Nuclear power has provided a large amount of electric energy for human. It has the potential to be a major, global, scalable, and carbon-free energy source in the future. Nuclear power has serviced human beings as a continuous supply for the energy for more than sixty years since 1954, when a small Obninsk plant was founded in Russia. By the year 2019, more than four hundred and forty nuclear power plants in the world were producing about $10 \%$ of the electricity [1-3]. The three largest countries in the world for nuclear power generation are America, Japan, and France. America has more than 100 nuclear power units with a total capacity of 98.2 GW. In the year 2019, the generated nuclear power in America accounts for more than $30 \%$ of the total nuclear power in the world with the amount of 809 TWh [4]. Japan is developed in nuclear power that it is the second largest producer of nuclear power, where the nuclear power accounts for one-third of the country's total electricity generation [5]. In France, the nuclear power accounts for more than $70 \%$ of the country's electricity generation based on fiftyeight operational units with the installed capacity of 63.1 
GW [6]. Although the nuclear power provides the energy to support the development of human, it also caused many thorny problems. Nuclear waste storage has always been a vexing and intractable problem. As we know, the nuclear waste is one kind of radioactive scrap that has a significant impact on human health if not disposed properly, and the average life of a nuclear reactor is just about a few decades. As a result, more and more nuclear waste is released every year. Researches have put forward various possible methods to store the waste nuclear after its reactor after considering different factors, such as the policies and techniques. Geological storage in deep georeservoir seems to be the most potential possibility for the disposal of nuclear waste that has caused high attention in the field. It means that the nuclear waste is to be transferred and stored promptly in a repository in the deep underground target formation once it is removed from the reactor.

Scholars at home and abroad have carried out a lot of researches on the underground storage of nuclear waste. The general design of the deep geological storage chamber requires a shielding tank that to cover the nuclear waste. The tank is then placed in a host rock formation. At present, different kinds of rock formations have been discussed for the feasibility of nuclear waste storage. In 2007, McKinley et al. [7] have published a good overview on the developing process about the choices for the stratigraphic formation. To summarize, the formations with rock types such as salt rock, clay stone, and granite are the possible targets to be host rocks for geological storage of nuclear waste. Based on a series of experiments, Jia et al. [8] analyzed the storage of nuclear waste in saturated hard clay; they also established an elastoplastic damage model for the deformation of the surrounding rock under a complex thermal-hydromechanical condition. Moog et al. [9] reported the ultralow seepage characteristics of granite and considered the storage of nuclear waste in a granite formation. Plúa et al. [10] introduced a large-scale modeling of the underground storage of high-level radioactive waste into Callovo-Oxfordian claystone and proposed a new method of numerical analysis. In their numerical work, the chamber of nuclear waste is considered to be stored in a deep formation of claystone, which has been selected as an industrial trial plot for geological disposal in France. Bentonite has favourable characteristics of plasticity, swelling capacity, colloid filtration, low hydraulic conductivity, high retardation of key radionuclides, and the stability in complex geological environments that it is treated as one kind of security component in the industrial storage engineering for different types of the nuclear waste [11]. Abdel-Karim et al. [12] collected the sand and sandstone samples from the Inshas rad-waste disposal site and examined the geochemical-physical properties in the Atomic Energy Agency. The results show that the samples has high contents of the interstitial $\mathrm{Fe}_{2} \mathrm{O}_{3}$ and $\mathrm{Al}_{2} \mathrm{O}_{3}$, which are important components to prevent the pollutant transport via adsorption. The Inshas rad-waste disposal site has a high possibility to meet the requirements of the nuclear waste storage as the presented high contents of the interstitial $\mathrm{Fe}_{2} \mathrm{O}_{3}$ and $\mathrm{Al} 2 \mathrm{O} 3$ were important agents for preventing pollutants transport via adsorption. Based on the field data that were collected from a specific spot from the southeastern coast of Sweden and the experimental results that were obtained from the Aspo Hard Rock Laboratory on, Tiren et al. [13] adopt a three-dimensional (3D) visualization method to model a hypothetical site for the storage of a high-level nuclear waste (HLNW). In their model, the chamber is located in the granitoid formation of the transScandinavian igneous belt with a depth of 500 meters. The research results show that the hypothetical conditions are of great feasibility for the storage of high-level nuclear waste. In 2010, Streimikiene and Mikalauskiene [14] analyzed and compared the challenges in the storages of geological carbon and nuclear waste in Lithuania. They also evaluated the cost for the development of the nuclear and carbon capture as well as the storage technologies. That is because Lithuania was faced with the final closure of the Ignalina nuclear power station and the storage of nuclear waste in that year. In China, researchers have conducted a lot of survey analysis from the surface and the subsurface aspects by the mapping and underground borehole exploration practices in the candidate sites. They have gotten comprehensive geological, hydrogeological, and geophysical data. The final result is that the Xinchang site in the Beishan region was selected as China's first underground research laboratory site [15]. Although scholars have considered couplings in the storage of nuclear waste in coal seam, few people take the characteristics of gas-saturated environment into consideration.

The geological storage of nuclear waste causes complex changes to the storage chamber and rocks. Their nature and performance are expected to change according to the internal and external conditions through the whole heating and cooling process of nuclear waste. As these processes donate potential influences on the engineering safety, it is necessary to identify and understand the environment changes in the surrounding rock profoundly in order to ensure the relevant safety requirements. Among the environment changes induced by nuclear waste storage, the thermohydro-mechanical-chemical (THMC) couplings are difficulties that urgently need to be resolved. Bernier et al. [16] points out that the complicated interactions among the thermofield, hydrofield, mechanical field, and chemical fields would affect the transport of radionuclide in the storage chamber and its surrounding environment. The ultimate degree of influence depends on the dynamic nature of the waste and the surroundings. By using the thermohydrological variables, Sasaki and Rutqvist [17] developed a methodology to approximately represent the stress in host rock and the changes of permeability that were induced by stress. A coupled thermo-hydro-mechanical simulation by using a TOUGH-FLAC simulator was established. Research results show that the developed methodology in the TH-coupled simulation matches the calculated data from the THMcoupled simulation over a simulated timeframe of over 10,000 years. To research the responses of the surrounding rocks under thermal loads under the background of deep geological radioactive waste storage, the French National Radioactive Waste Management Agency did a series of experiments including the in situ experiments at the Meuse/Haute-Marne Underground Research Laboratory [18]. The 
thermomechanical behaviors of the steel sleeve, equipped with strain gauges, displacement sensors, and temperature sensors are well discussed. They also monitored the evolution of the annular space and studied the thermo-hydromechanical behavior of the near or far rock under different pore pressures and temperatures through the sensors that are installed in peripheral boreholes. Considering the change of extreme climate, Boulton et al. [19] simulated the thermohydro-mechanical impacts of extreme climate on the lithosphere, which might extend deep into the reservoir. The research results show that the glaciation has impacts on a depth scale. It required to be considered in a safety analysis for deep lithosphere storage of long-lived radionuclides in areas that have been prone to glaciation in the past. Holton et al. [20] described an efficient means to evaluate the maximum temperature constraint of the deformation that is to place a waste container. They find that sodium montmorillonite will undergo mineral alteration when the temperature increases significantly, which will reduce the expansion property of the material. At an approximate underground environment of nuclear waste storage in laboratory, Zhang [21] observed the thermo-hydro-mechanical behaviors of the indurated Opalinus clay rocks extensively. The results show that the maximum temperature for nuclear waste is over one hundred degrees centigrade. In large-scale deep geological disposal, the hydrogen embrittlement may occur in titanium vessels once oxygen is depleted. Therefore, Zhang et al. [22] predicted the potential danger of the high-level nuclear waste container caused by embrittlement; the hydrogen entry into titanium was studied at different temperatures in a simulated deep geological environment of Beishan, which was the preselected HLNW storage area in China. Ström et al. [23] presented an overview of the bedrock and surface modeling work that comprises a major part of the site characterization in Sweden, called site descriptions. The sitedescriptive models involves a multidisciplinary interpretation of geology, rock mechanics, thermal properties, hydrogeology, hydrogeochemistry, transport properties, and ecosystems using input in the form of available data for the surface and from deep boreholes. Salama et al. [24] explored the anisotropic geologic repositories on the high-level nuclear waste disposal. Numerical results show that even a slight difference in anisotropy of thermal conductivity of host rock with direction could have interesting effects on temperature fields, and the temperature contours are aligned more towards the principal direction of anisotropy. Furthermore, it is found that the larger the peak temperature in the buffer zone, the smaller the anisotropy angle and vice versa. To better understand the processes of geological nuclear waste storage, Dupray et al. [25] proposed a case study for sensitivity analysis by using a thermo-hydro-mechanical finite element approach including a consistent thermoplastic constitutive model for unsaturated soils. The model features a coupled thermo-hydro-mechanical approach of the water retention curve. Various couplings were studied separately and in combination in order to determine the significance of each. The change of temperature caused by geological storage of nuclear waste has attracted the attention of most scholars; however, the study on the coupled interactive effects among temperature, surrounding rock/coal, and gas in the nuclear waste storage is still lacking.

To study the storage of nuclear waste in gas-saturated deep coal seam, this paper carried out a mechanical modeling and numerical simulation work. The theoretical heat-solidgas coupling model has three components of heat transfer, gas seepage, and solid deformation that are governed by three conservation equations. Before the establishment of thermal energy conservation equation, the temperature decay evolution of nuclear waste was well discussed. For coal deformation, the mechanical equilibrium is obviously applicable with the considerations of thermal stress and gas pressure. The migration of gas in both coal matrix and fracture network satisfies the mass conservation equation, and gas flow obeys a Darcy's law. By using a PDE solver of COMSOL Multiphysics with MATLAB, the approved mechanical model is successfully implemented into a numerical model and solved as a numerical simulation in Section 3. Section 4 analyzes and quantifies the numerical results on the storage of nuclear waste in gas-saturated deep coal seam. The conclusions and understandings are drawn in the last Section 5, which are expected to provide a deep understanding on the geological storage of nuclear waste.

\section{Modeling on the Storage of Nuclear Waste}

There are three typical fields of the diffusion of thermal energy, deformation of coal seam, and the escaping of gas that interplays each other in the storage of nuclear waste in a gas-saturated coal seam. Before modeling, we assume that the surrounding coal is in close contact with the nuclear waste tanks. The governing equation for each physical field is established in this section as follows.

2.1. Evolution of Temperature with Time for the Nuclear Waste Tank. As the residual reaction of nuclear waste is exhausted, the temperature of the nuclear waste storage chamber decreases gradually [26]. In order to clarify the temperature attenuation evolution of nuclear waste itself, related data are collected and analyzed from the domestic and overseas research achievement, a simple and practical semiempirical curve for the evolution of temperature is obtained. Figure 1 shows the temperature attenuation curve of nuclear waste, in which the points represent the reported date by Zheng et al. [27]. From Figure 1, one can find that the temperature of nuclear waste decreases with the storage time from the initial temperature of $370 \mathrm{~K}$ to the final temperature of $298 \mathrm{~K}$ after about 4000 years. In the first 1500 years, the temperature of nuclear reactor decreases at an increasing rate, whereas the decreasing rate of temperature slows down gradually in the later 2500 years. Thus, the evolution of temperature with time for the nuclear reactor can be fitted by a logistic function as

$$
T=291.8+\frac{75.2}{1+(t / 1638.2)^{3.52}}
$$

where $T$ is the temperature of the nuclear reactor, $\mathrm{K}$ and $t$ is the storage time in unit of year. As is seen in Figure 1, the 


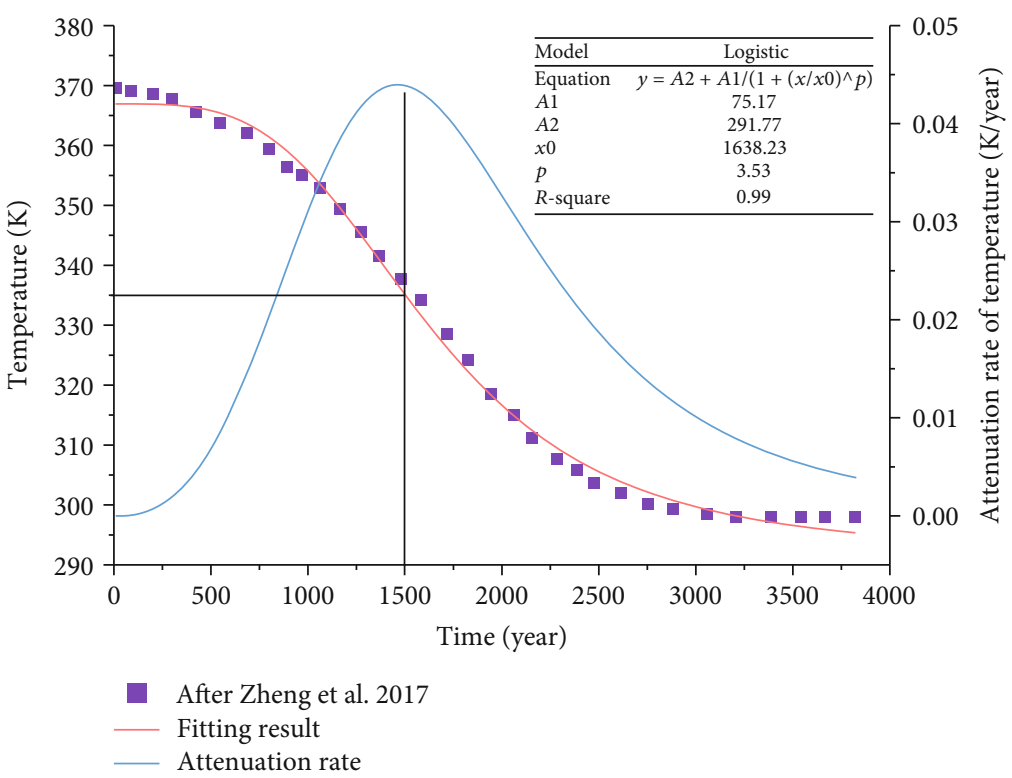

FIGURE 1: Temperature attenuation curve of nuclear reactor.

fitting result is well matched with the reported data from Zheng et al. [27].

2.2. Diffusion of Thermal Energy. The total heat flux in coal seam contains the heat conduction and convection that can be expressed as [28]

$$
v_{T}=-K_{T} \nabla T+\rho_{g} \rho_{c} C_{g} v_{g}
$$

where $v_{T}$ is the total heat flux velocity, $\left(\mathrm{J} /\left(\mathrm{m}^{2} \cdot \mathrm{s}\right)\right) ; K_{T}$ is the effective coefficient for the thermal conductivity of gassaturated coal, $(\mathrm{J} /(\mathrm{m} \cdot \mathrm{s} \cdot \mathrm{K})) ; \Delta T$ is the increase of temperature, $\mathrm{K} ; \rho_{g}$ and $\rho_{c}$ represent the densities of gas and coal, respectively, $\mathrm{kg} / \mathrm{m}^{3} ; C_{g}$ is the specific heat constants of gas, $\mathrm{kJ} /(\mathrm{kg} \cdot \mathrm{K})$; and $v_{g}$ is the vector of gas velocity, $\mathrm{m} / \mathrm{s}$.

According to Darcy's law, $v_{g}$ can be expressed as $[29,30]$

$$
v_{g}=-\frac{k}{\mu} \nabla p_{g}
$$

where $\mu$ donates the dynamic viscosity of the gas, Pa.s; $k$ is the permeability of the coal seam, $\mathrm{m}^{2}$; and the pressure gradient $\nabla p_{g}, \mathrm{~Pa} / \mathrm{s}$, can be expressed as

$$
\nabla p=\frac{\partial p_{g}}{\partial x} i+\frac{\partial p_{g}}{\partial y} j+\frac{\partial p_{g}}{\partial z} k
$$

The energy conservation in the coal seam obeys an energy conservation equation as [31]

$$
\frac{\partial\left(C_{q} T\right)}{\partial t}+p_{g} \nabla \cdot v_{g}+\nabla \cdot v_{T}=Q_{T}
$$

where $C_{q}$ donates the specific heat capacity of gas-saturated coal, kJ/(kg.K).

Substituting Equations (2)-(4) into Equation (5), one obtains the energy conservation equation as

$C_{q} \frac{\partial T}{\partial t}+p_{g} \nabla \cdot\left(-\frac{k}{\mu} \nabla p_{g}\right)-K_{T} \nabla^{2} T+\rho_{c} C_{g} \nabla \cdot\left[\rho_{g}-\frac{k}{\mu} \nabla p_{g}\right]=Q_{T}$.

2.3. Deformation of Coal Seam. During the storage period of nuclear waste, the changes of temperature and gas pressure will trigger the gas desorption deformation and thermal expansion. According to Teng et al. [32], the deformation that was induced by gas desorption is related with the gas pressure and the change of temperature as

$$
\varepsilon_{s}=\frac{\varepsilon_{L} p_{g}}{P_{L}+p_{g}} e^{-c_{T} \Delta T /\left(1+c_{p} p_{g}\right)},
$$

where $\varepsilon_{s}$ is the gas sorption-induced volumetric stain; $\varepsilon_{L}$ is the deformation parameter; and $P_{L}, c_{T}$, and $c_{p}$ are the coefficients for gas sorption. Thermal expansion $\varepsilon_{T}$ is linearly dependent on the change of temperature as $\varepsilon_{T}=\alpha_{T} \Delta T$, where $\alpha_{T}$ is the coefficient of thermal expansion.

To establish the deformation model, the coal seam is assumed to deform as one kind of elastic material where the stress $\sigma_{i j}$ and strain $\varepsilon_{i j}$ has following relation [33]:

$$
\sigma_{i j}=2 G \varepsilon_{i j}+\left(\frac{2 G v}{1-2 v} \varepsilon_{k k}+\alpha p_{g}-K \alpha_{T} T-K \varepsilon_{s}\right) \delta_{i j}
$$

where $\alpha$ is Biot's coefficients for coal; $G$ and $K$ are the shear and bulk modulus of coal, MPa, respectively; $v$ is Poisson's 


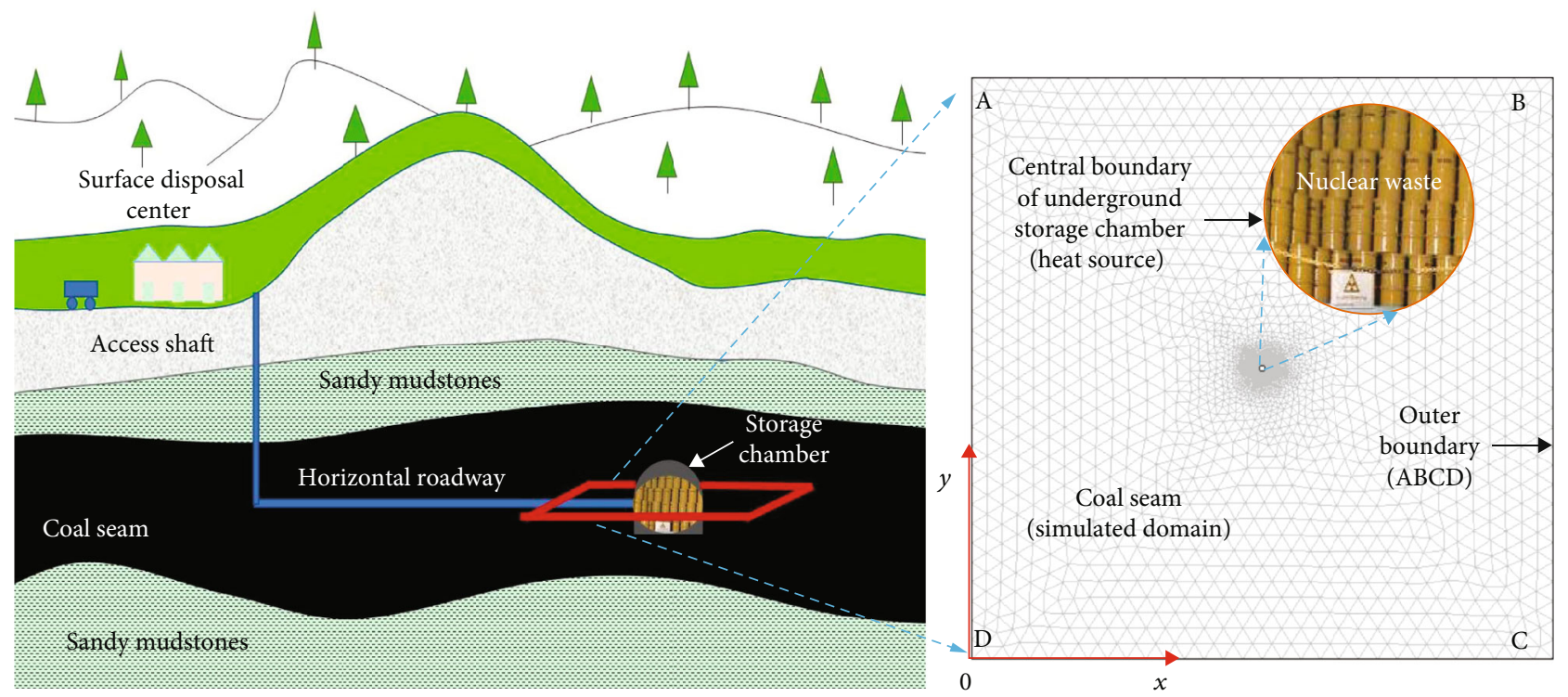

(a) Schematic diagram of nuclear waste storage in coal mine

(b) Numerical geometry: a top view section

Figure 2: Schematic diagram of the numerical model.

TABle 1: Parameters for numerical simulation.

\begin{tabular}{lc}
\hline Parameter & Value used \\
\hline Elasticity for coal $(E, \mathrm{MPa})$ & 2713 \\
Poisson's ratio $(v)$ & 0.339 \\
Coal density $\left(\rho_{c}, \mathrm{~kg} / \mathrm{m}^{3}\right)$ & $1.25 \times 10^{3}$ \\
Coefficient for sorption deformation $\left(\varepsilon_{L}, \mathrm{~kg} / \mathrm{m}^{3}\right)$ & 0.0156 \\
Initial permeability of coal matrix $\left(k_{m 0}, \mathrm{mD}\right)$ & 0.002 \\
Initial permeability of coal fracture system $\left(k_{f 0}, \mathrm{mD}\right)$ & 1 \\
Initial porosity of coal matrix $\left(\phi_{m 0}\right)$ & 0.05 \\
Methane dynamic viscosity $(\mu, \mathrm{Pa} \cdot \mathrm{s})$ & $1.84 \times 10^{-5}$ \\
Langmuir volume constant $\left(\eta_{s}, \mathrm{~m}^{3} / \mathrm{kg}\right)$ & 0.048 \\
Langmuir pressure constant $\left(P_{L}, \mathrm{MPa}\right)$ & 1.57 \\
Pressure coefficient $\left(c_{p}, \mathrm{MPa}{ }^{-1}\right)$ & 0.07 \\
Temperature coefficient $\left(c_{T}, \mathrm{~K}^{-1}\right)$ & 0.02 \\
Pressure at standard condition $\left(p_{a}, \mathrm{MPa}\right)$ & 0.103 \\
Thermal expansion coefficient for solid coal matrix $\left(\alpha_{T}, \mathrm{~K}^{-1}\right)$ & $2.4 \times 10^{-5}$ \\
Specific heat capacity of gas $\left(C_{g}, \mathrm{~kJ} /(\mathrm{kg} \cdot \mathrm{K})\right)$ & 1.25 \\
Specific heat capacity of coal $\left(C_{q}, \mathrm{~kJ} /(\mathrm{kg} \cdot \mathrm{K})\right)$ & 1.62 \\
Thermal conductivity of coal $\left(K_{T}, \mathrm{~J} /(\mathrm{m} \cdot \mathrm{s} \cdot \mathrm{K})\right)$ & 0.2 \\
\hline
\end{tabular}

ratio; and $\delta_{i j}$ donates the Kronecker delta which is defined as 1 if $i=j$ and 0 if $i \neq j$.

2.4. Gas Escaping in Coal Seam. The storage of nuclear waste leads to a redistribution of coalbed methane in coal and rock formations as it changes the temperature. Coal is often treated as a dual-porous medium that contains the coal matrix and the fracture network; the escaping of gas in both the matrix and fracture systems obeys the mass conservation equation in same type as [34]

$$
\frac{\partial m_{g}}{\partial t}+\nabla \cdot\left(\rho_{g} v_{g}\right)=Q_{g}
$$

in which, $Q_{g}$ is the gas source; the gas density $\rho_{g}$ can be expressed by the gas pressure as

$$
\rho_{g}=\frac{M_{g}}{R T} p_{g}
$$



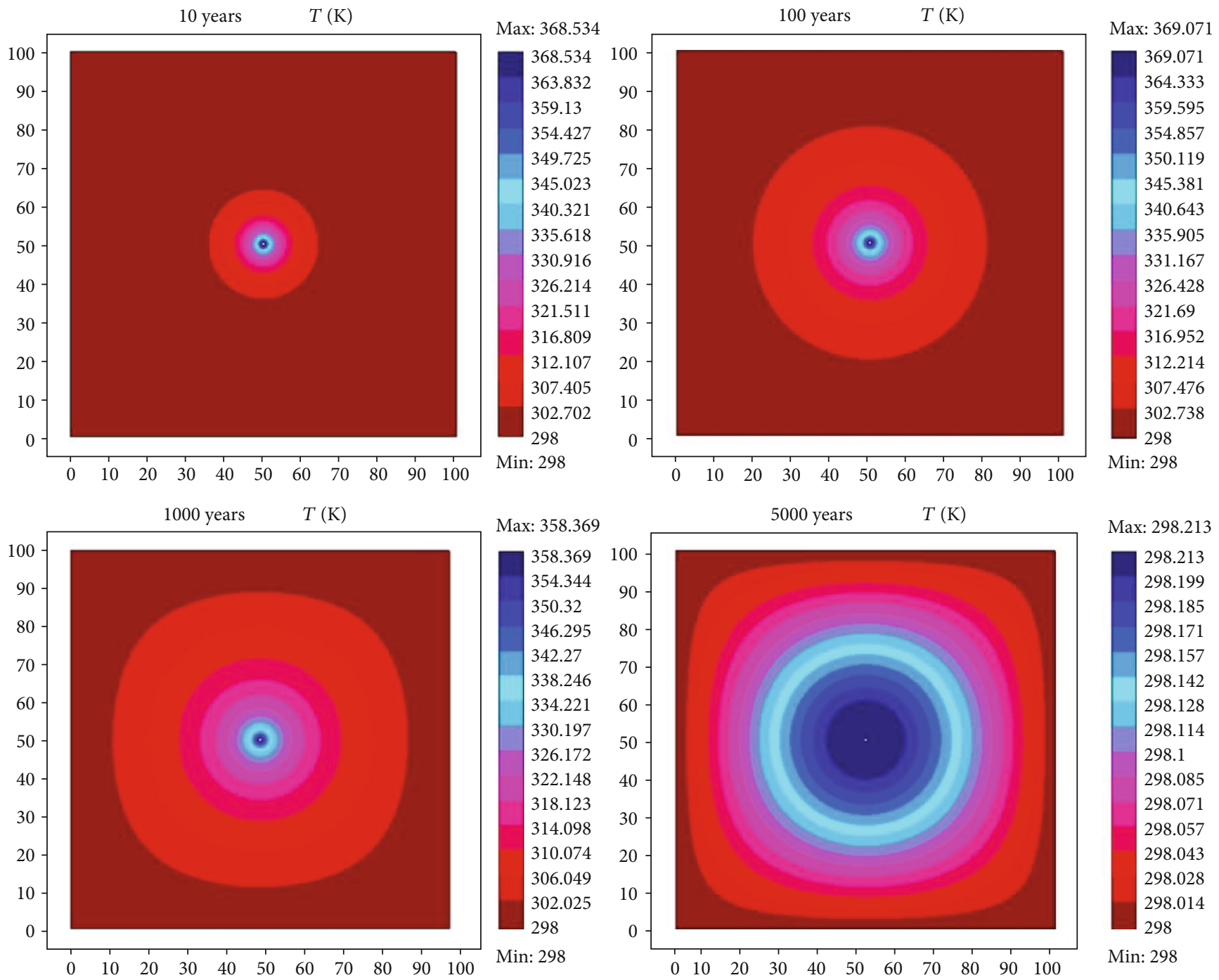

FIGURE 3: Spatial distribution of the reservoir temperature after 10, 100, 1000, and 5000 years.

where $R$ and $M_{g}$ are the universal gas constant and the molar mass of gas.

According to $[35,36]$, the transfer of gas in coal matrix and fracture network is proportional to the pressure gradient as

$$
Q_{g}=\frac{M_{g}}{\tau R T}\left(p_{g m}-p_{g f}\right)
$$

where $\tau$ is a coefficient for the desorption time and $p_{g m}$ and $p_{g f}$ represent the gas pressures in coal matrix and coal fracture network, $\mathrm{MPa}$, respectively.

In coal matrix, gas is stored in both adsorption state and free state. The gas content $m_{g f}$ can be expressed as

$$
m_{g m}=\rho_{g} \phi_{m}+\frac{\eta_{s} p_{g}}{P_{L}+p_{g}} e^{-c_{T} \Delta T /\left(1+c_{p} p_{g}\right)}
$$

where $\eta_{s}$ is the adsorption volume coefficient, $\mathrm{kg} / \mathrm{m}^{3}$. In the fracture network, gas is stored in free gas state, where the gas content $m_{g f}$ is

$$
m_{g f}=\rho_{g} \phi_{f}
$$

where $\phi_{m}$ and $\phi_{f}$ are the porosity of coal matrix and fracture network, respectively.

The permeability of coal matrix and fracture network can be expressed as $[33,35]$

$$
\begin{gathered}
k_{m}=k_{m 0}\left[\frac{1+\alpha\left(\Delta \varepsilon_{v}+\Delta p_{m} / K_{s}-\Delta \varepsilon_{s}-\alpha_{T} \Delta T\right)}{\phi_{m 0}}\right]^{3}, \\
k_{f}=k_{f 0} e^{-3 c_{f} \Delta \sigma_{i j}},
\end{gathered}
$$

where $c_{f}$ is the compressibility for the fracture network. 


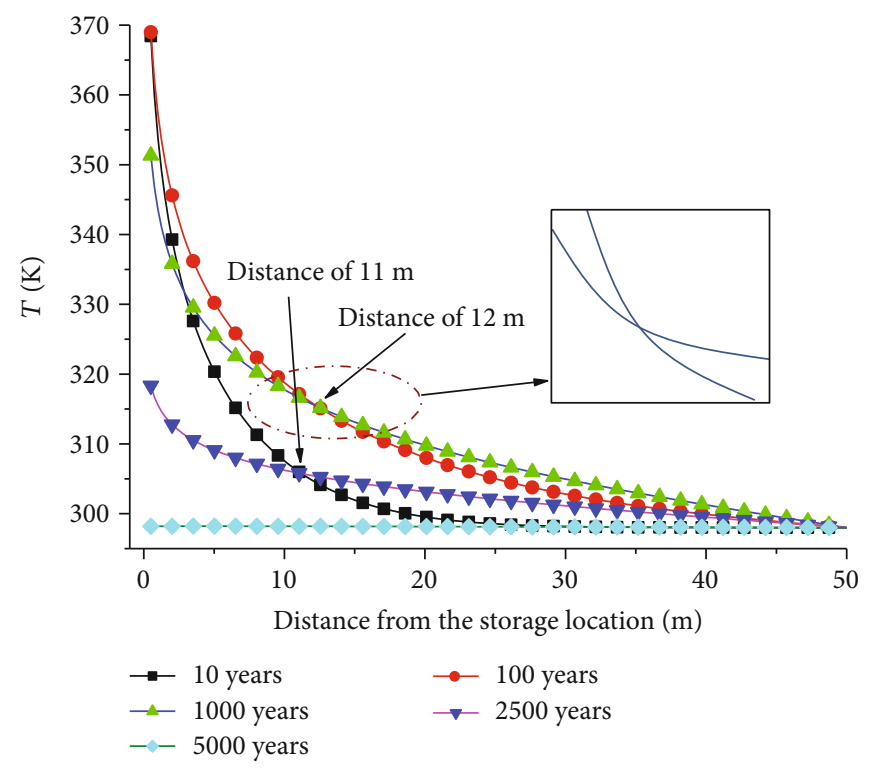

FIGURE 4: Evolution of reservoir temperature with the storage distance after different storage times.

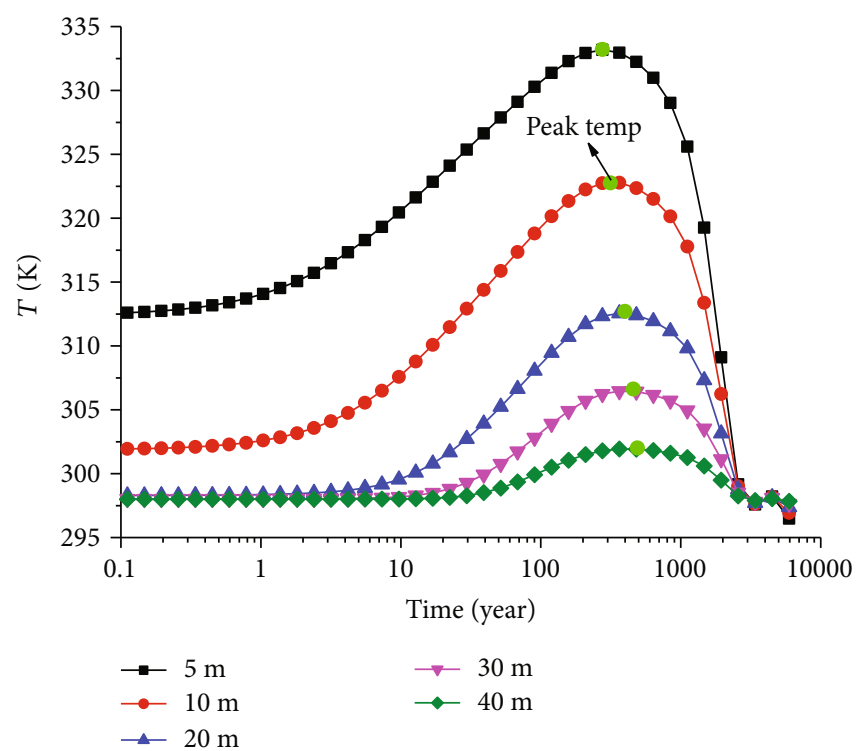

Figure 5: The evolution of reservoir temperature with time at different storage distances.

Equations (6), (8). and (9) make up a fully coupled heatsolid-gas coupling model for the storage of waste nuclear in deep coal seam. It is obviously difficult to solve an analytical solution for this proposed nonlinear partial differential model. However, the numerical solution can be well solved by a PDE solver, COMSOL Multiphysics with MATLAB in a powerful PDE-based multiphysics modeling environment.

\section{Geological Environment and Model Establishment}

The buried depth of target coal seam is $800 \mathrm{~m}$, and there is a few of underground water above or below the formation. The roof and floor of the coal seam are sandy mudstone that has not been disturbed significantly from coal mining. The nuclear waste is supposed to be stored in the coal chambers that are remained in the previous coal mining practice. Figure 2(a) shows the schematic diagram of nuclear waste storage in deep coal seam. One can find a vertical shaft and a horizontal roadway for the access of storage chamber. The nuclear waste is processed at the ground surface disposal center and then transported to the storage chamber.

To simplify the calculation, a planar slice in Figure 2(b) can feasibly represent the basic computational area based on the plane strain hypothesis. The rectangular geometry of $\mathrm{ABCD}$ is selected for simulation with a circular storage chamber. The length of the rectangular model is $100 \mathrm{~m}$, and the diameter of the central chamber is $8 \mathrm{~m}$. In coal seam, the in situ gas pressure and temperature are $3.5 \mathrm{MPa}$ and $298 \mathrm{~K}$, respectively. The displacements for boundary AD 

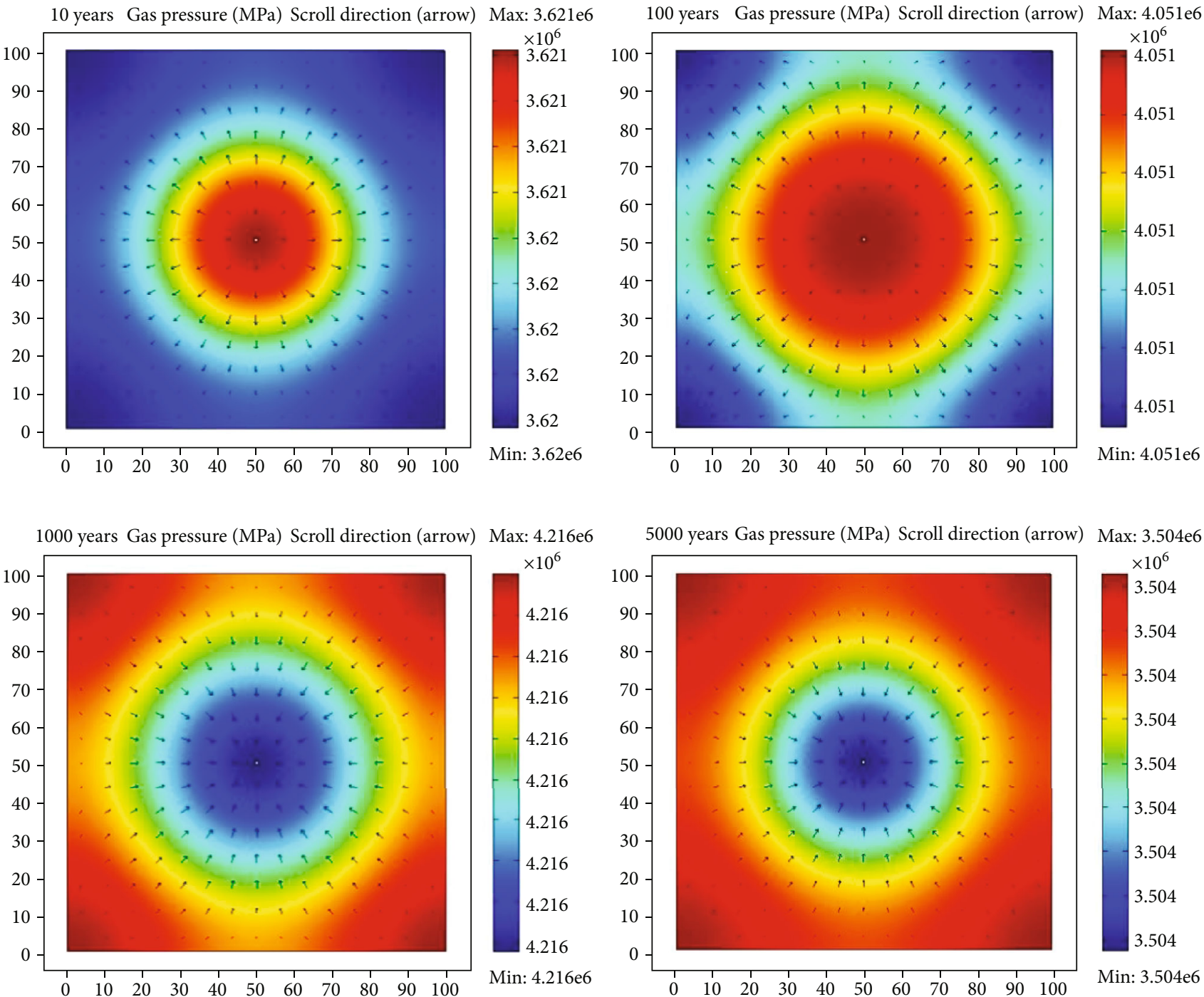

Figure 6: Distribution of gas pressure.

and $\mathrm{BC}$ are restrained in the $x$-direction while the displacements for boundary $\mathrm{AB}$ and $\mathrm{DC}$ are restrained in the $y$ -direction. The central boundary is free for stress and constraint for displacement in the model. For the situation of coal seam gas, the boundary ABCD is treated as a symmetric boundary in both the matrix and fracture system where the gas flow and distribution have symmetry to these boundaries, and the central boundary is an airtight boundary with no flux. For the transfer of temperature, the boundary ABCD is given a constant temperature of $298 \mathrm{~K}$ while the central boundary has a time-dependent temperature that has been illustrated in Equation (1). Other simulation parameters are taken from literatures or determined from the conventional mechanical properties of coal and rock. Table 1 lists the main simulation parameters.

\section{Analysis of Numerical Results}

4.1. Spatial Evolution of Reservoir Temperature. Figure 3 shows the spatial distribution of the reservoir temperature after different storage time of 10, 100, 1000, and 5000 years. From Figure 3, one can find that the affected area of reservoir temperature gradually grows larger with the storage time of the nuclear waste. After the first 10 years of storage, the influence of nuclear waste on reservoir temperature mainly occurs within a range of about $15 \mathrm{~m}$ from the storage chamber, where the decreasing gradient of temperature with the increasing distance is very large. The storage of the nuclear waste has little impact in the more open range of area with the distance that is larger than $15 \mathrm{~m}$. After the storage of 100 years, the increment of reservoir temperature is mainly concentrated within a distance of about 30 meters from the storage chamber, whereas the average temperature increment of the reservoir does not exceed $2^{\circ} \mathrm{C}$ at the further area. After the storage of 1000 years, the affecting distance of reservoir temperature by the central storage of nuclear waste reaches to 40 meters. By this time, the maximum value of reservoir temperature is significantly reduced to $358.4^{\circ} \mathrm{C}$. This is because the temperature of nuclear waste decreases a lot after 1000 years. When the storage time reaches 5000 years, the 


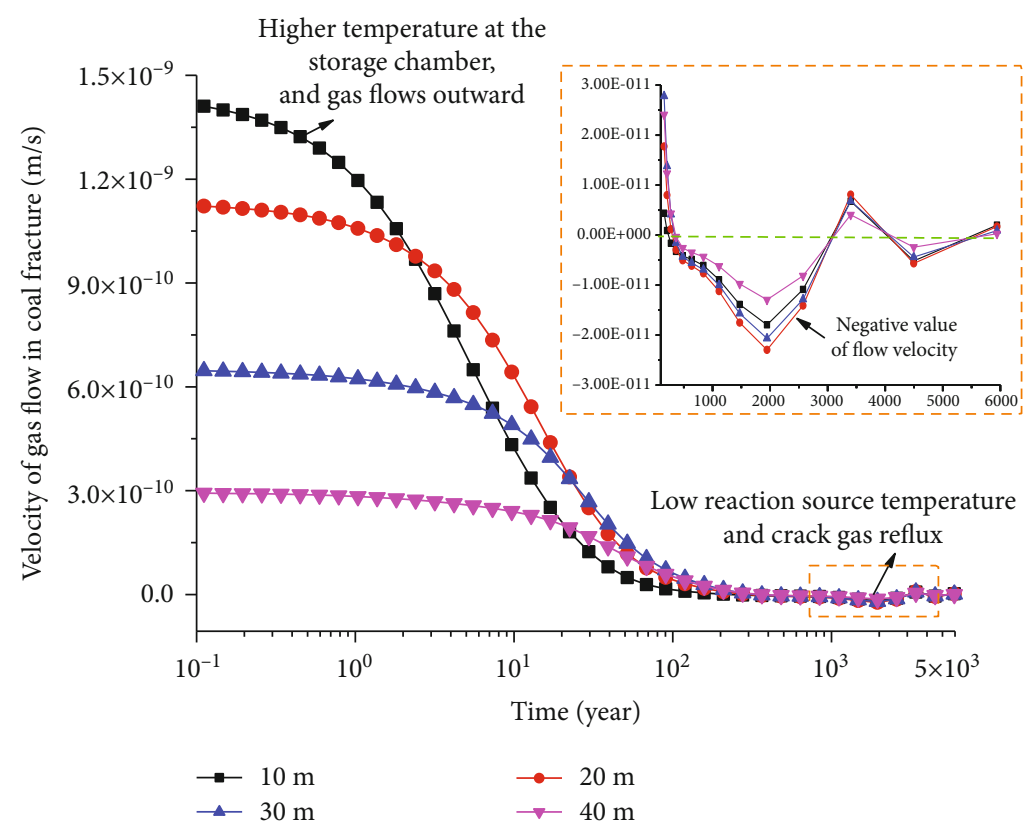

FIGURE 7: Velocity of gas flow in the fracture network.

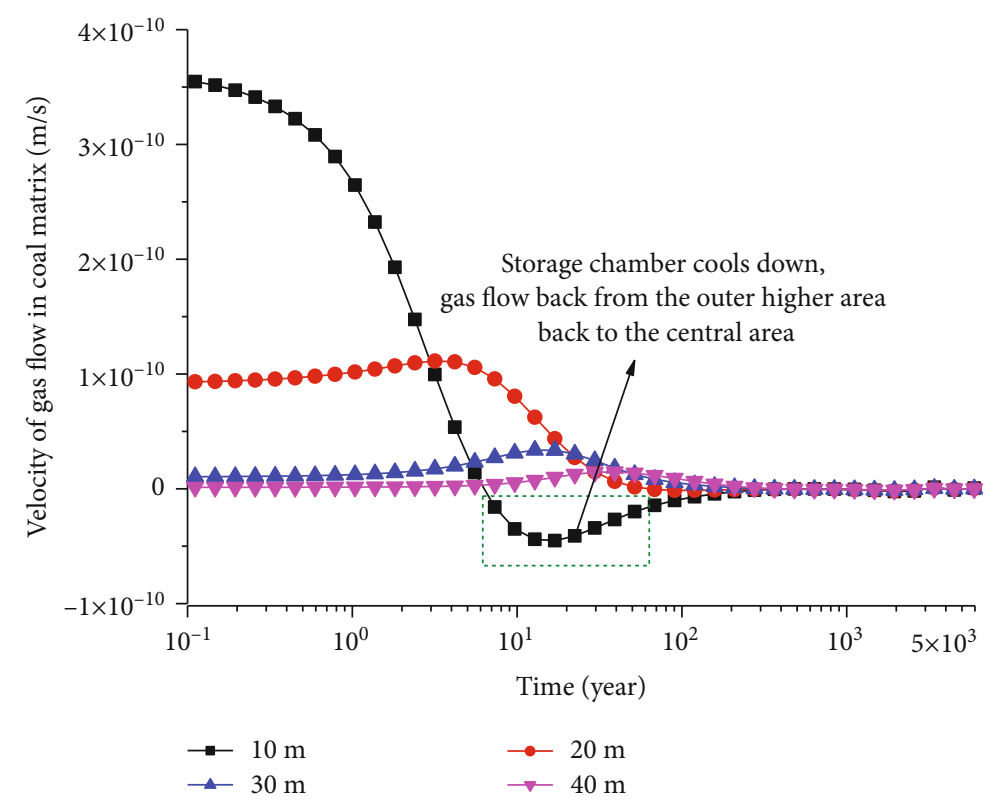

Figure 8: Velocity of gas flow in the coal matrix.

temperature of the whole coal seam drops to its initial temperature of $298 \mathrm{~K}$ after the depletion of the stored nuclear waste reaction.

Figure 4 is the quantitative evolution of reservoir temperature with the storage distance at different storage times. It shows that the nuclear waste source heats up the very adjacent surrounding coal reservoir firstly and then be heated by the far-field reservoir. As a result the evolution curves of reservoir temperature with the storage distance after different storage time get crossed, and the crossing points get close to the central chamber with storage time.
4.2. Evolution of Reservoir Temperature over Time. Figure 5 reflects the evolution of reservoir temperature over time at the storage distance of 5,10,20,30, and $40 \mathrm{~m}$ from the nuclear waste chamber. It shows that the temperature rises firstly and then decreases over time. Due to the continuous decay of the nuclear waste reaction over time, the heat produced the nuclear itself decreases gradually; thus, the temperature of nuclear waste deceases over time. In the earlier stage of nuclear waste storage (about 200 to 400 years), the nuclear reaction heats up the surrounding coal seam, as a result the temperature rises gradually. When the nuclear reaction 
weakens, the temperature of the nuclear waste decreases, and the heat in heated seam conducts both toward to the central and the outer areas that resulting in a decrease of the temperature in coal seam. Taking the distance of $5 \mathrm{~m}$ as an example, one can find that the peak temperature is $333^{\circ} \mathrm{C}$ after a storage time of 200 years. The reservoir temperature rises with time before this time and decreases after then. Figure 5 also shows that the peak temperature value decreases with the distance from the central chamber, and the corresponding storage time for the peak temperature increases. For example, the peak temperature at the distance of $10,20,30$, and $40 \mathrm{~m}$ are $322^{\circ} \mathrm{C}, 312^{\circ} \mathrm{C}, 306^{\circ} \mathrm{C}$, and $301^{\circ} \mathrm{C}$, at the corresponding storage year of $275,352,371$, and 398, respectively.

4.3. Evolution of Gas Pressure in Coal Seam. Figure 6 represents to the distribution of gas pressure in coal seam after the storage time of $10,100,1000$, and 5000 years. The change of temperature results in a series of coal-gas-temperature couplings, such as the enhancement of gas sorption, the expansion of coal matrix, and the increment of gas pressure. In Figure 6, it can be clearly seen that the gas pressure in the region nearby the central storage chamber is higher than that at the far region after 10 and 100 years, and coal seam gas flows outward from the central storage chamber to the outer area. At the storage time of 1000 and 5000 years, the temperature in the outer area is higher than the central area, where the gas flows back. This is the response of the change of reservoir temperature, as the gas pressure is sensitive to the changes of temperature.

4.4. Gas Flow in Coal Seam. Figures 7 and 8 show the velocity of gas flow at different distances in the coal matrix and the fracture network, respectively. From Figures 7 and 8, one can find that the initial velocity of gas flow decreases gradually with the increase of distance. For coal fracture network, the initial values are $1.42,1.11,0.65$, and $0.3 \mathrm{~nm} / \mathrm{s}$ at the position with distance of 10, 20,30, and $40 \mathrm{~m}$, respectively. For coal matrix, the corresponding initial values of flow velocity are $0.35,0.1,0$, and $0 \mathrm{~nm} / \mathrm{s}$, respectively. Due to the high initial temperature of the nuclear waste and its fast cooling down, coal gas flows back. As a result, the velocity of gas flow decreases gradually or finally reverses to the opposite direction, especially at the region with short distance from the chamber. For example, gas flow is an obvious negative value at the distance of $10 \mathrm{~m}$ in coal matrix between the storage year that ranges from 6 to 110 .

\section{Conclusions}

In this study, a coupled heat-solid-gas model with three constitutional fields of heat transfer, coal deformation, and gas seepage is developed for to analyze the geological storage of nuclear waste in a gas-saturated deep coal seam. The model covers a series of interactive influences among temperature change, dual permeability of coal, thermal stress, and gas sorption. It is then applied to a numerical simulation in the PDE solver of COMSOL Multiphysics with MATLAB. Hence, the following conclusions can be drawn from this study:
(1) In the initial storage stage of 400 years, the nuclear waste storage heats up the surrounding coal seam firstly and then be heated by the far-field reservoir. After the storage of 100 years, the increment of reservoir temperature is mainly concentrated within a distance of about 30 meters from the storage chamber, while the average temperature increase of the reservoir does not exceed $2^{\circ} \mathrm{C}$ at the further area. After 1000 years, the affecting distance of reservoir temperature by the central storage of nuclear waste affects reaches to 40 meters

(2) The initial velocity of gas flow decreases gradually with the increasing distance from the storage chamber. Gas pressure in the region nearby the central storage chamber is higher than that in the far region after 10 and 100 years, and coal seam gas flows outward from the central storage chamber to the outer area. After the storage time of 1000 and 5000 years, the temperature in the outer region is higher than the central region, and the gas flows back

The proposed heat-solid-gas model and simulation analysis are expected to improve the current understandings on the geological storage of nuclear waste.

\section{Data Availability}

Some calculation parameters are used in the numerical simulation in this work. All these parameters are derived from the historical documents and related experimental studies that are listed in Table 1.

\section{Conflicts of Interest}

I would like to make the following statement about the article's conflict of interest on behalf of all co-authors: (a) the article is organized under the joint efforts of all the authors, and the authors have agreed on the order in which the papers should be signed. (b) This article is the original work that has never been published in other places previously and will not be submitted for publication elsewhere during this period of submission. (c) The manuscript has been approved for submission by all the authors listed.

\section{Acknowledgments}

The paper is supported by the National Natural Science Foundation (52004285, U1910206), the Fundamental Research Funds for the Central Universities (2021YQNY06) from China University of Mining and Technology-Beijing, and the Open Fund of Key Laboratory of Safety and Highefficiency Coal Mining (JYBSYS2019101). This paper expresses deep gratitude to all the above supports.

\section{References}

[1] D. Themann and A. Brunnengräber, "Using socio-technical analogues as an additional experience horizon for nuclear waste management a comparison of wind farms, fracking, 
carbon capture and storage (CCS) with a deep-geological nuclear waste disposal (DGD)," Utilities Policy, vol. 70, no. 6, p. 101181, 2021.

[2] F. G. F. Gibb, "High-temperature, very deep, geological disposal: a safer alternative for high-level radioactive waste?," Waste Management, vol. 19, no. 3, pp. 207-211, 1999.

[3] Z. Y. Ma, R. Pathegama Gamage, T. Rathnaweera, and L. Kong, "Review of application of molecular dynamic simulations in geological high- level radioactive waste disposal," Applied Clay Science, vol. 168, no. 2, pp. 436-449, 2019.

[4] L. Ortiz, G. Volckaert, and D. Mallants, "Gas generation and migration in Boom Clay, a potential host rock formation for nuclear waste storage," Engineering Geology, vol. 64, no. 2-3, pp. 287-296, 2002.

[5] F. Liang and X. G. Liu, "Analysis on the characteristics of geologic disposal waste arising from various partitioning and conditioning options," Annals of Nuclear Energy, vol. 85, no. 11, pp. 371-379, 2015.

[6] J. P. Busby, J. R. Lee, S. Kender, J. P. Williamson, and S. Norris, "Modelling the potential for permafrost development on a radioactive waste geological disposal facility in Great Britain," Proceedings of the Geologists Association, vol. 126, no. 6, pp. 664-674, 2015.

[7] I. G. McKinley, W. Russell Alexander, and P. C. Blaser, "Development of geological disposal concepts," Radioactivity in the Environment, vol. 9, no. 6, pp. 41-76, 2007.

[8] Y. Jia, G. Duveau, and J. F. Shao, "Thermo-hydromechanical modeling in saturated hard clay and application to nuclear waste storage," in Soil and Rock Behavior and Modeling, ASCE Library, 2006.

[9] H. C. Moog, F. Bok, C. M. Marquardt, and V. Brendler, "Disposal of nuclear waste in host rock formations featuring highsaline solutions - implementation of a thermodynamic reference database (THEREDA)," Applied Geochemistry, vol. 55, no. 4, pp. 72-84, 2015.

[10] C. Plúa, M. N. Vu, G. Armand et al., "A reliable numerical analysis for large-scale modelling of a high-level radioactive waste repository in the Callovo-Oxfordian claystone," International Journal of Rock Mechanics and Mining Sciences, vol. 140, no. 4, p. 104574, 2021.

[11] A. E. Milodowski, S. Norris, and W. R. Alexander, "Minimal alteration of montmorillonite following long-term interaction with natural alkaline groundwater: implications for geological disposal of radioactive waste," Applied Geochemistry, vol. 66, no. 5, pp. 184-197, 2016.

[12] A. M. Abdel-Karim, A. A. Zaki, W. Elwan, M. R. el-Naggar, and M. M. Gouda, "Geological and contaminant transport assessment of a low level radioactive waste disposal site," Journal of Geochemical Exploration, vol. 197, no. 2, pp. 174-183, 2019.

[13] S. A. Tirén, P. Askling, and S. Wänstedt, "Geologic site characterization for deep nuclear waste disposal in fractured rock based on 3D data visualization," Engineering Geology, vol. 52, no. 3-4, pp. 319-346, 1999.

[14] D. Streimikiene and A. Mikalauskiene, "Analysis of possible geological storage of $\mathrm{CO}_{2}$ and nuclear waste in Lithuania," Renewable \& Sustainable Energy Reviews, vol. 14, no. 6, pp. 1600-1607, 2010.

[15] J. Wang, L. Chen, R. Su, and X. Zhao, “The Beishan underground research laboratory for geological disposal of highlevel radioactive waste in China: planning, site selection, site characterization and in situ tests," Journal of Rock Mechanics and Geotechnical Engineering, vol. 10, no. 3, pp. 411-435, 2018.

[16] F. Bernier, F. Lemy, P. de Cannière, and V. Detilleux, "Implications of safety requirements for the treatment of THMC processes in geological disposal systems for radioactive waste," Journal of Rock Mechanics and Geotechnical Engineering, vol. 9, no. 3, pp. 428-434, 2017.

[17] T. Sasaki and J. Rutqvist, "Estimation of stress and stressinduced permeability change in a geological nuclear waste repository in a thermo-hydrologically coupled simulation," Computers and Geotechnics, vol. 129, no. 1, p. 103866, 2021.

[18] F. Bumbieler, C. Plúa, S. Tourchi et al., "Feasibility of constructing a full-scale radioactive high-level waste disposal cell and characterization of its thermo-hydro-mechanical behavior," International Journal of Rock Mechanics and Mining Sciences, vol. 137, no. 1, p. 104555, 2021.

[19] G. Boulton, T. Chan, R. Christiansson et al., "Thermo-hydromechanical (T-H-M) impacts of glaciation and implications for deep geologic disposal of nuclear waste," Elsevier GeoEngineering Book Series, vol. 2, no. 1, pp. 299-304, 2004.

[20] D. Holton, S. Myers, G. Carta, A. Hoch, M. Dickinson, and N. Carr, "Application of a novel approach to assess the thermal evolution processes associated with the disposal of high-heatgenerating waste in a geological disposal facility," Engineering Geology, vol. 211, no. 8, pp. 102-119, 2016.

[21] C. L. Zhang, "Thermo-hydro-mechanical behavior of clay rock for deep geological disposal of high-level radioactive waste," Journal of Rock Mechanics and Geotechnical Engineering, vol. 10, no. 5, pp. 992-1008, 2018.

[22] Q. C. Zhang, Y. L. Huang, W. Sand, and X. Wang, "Effects of deep geological environments for nuclear waste disposal on the hydrogen entry into titanium," International Journal of Hydrogen Energy, vol. 44, no. 23, pp. 12200-12214, 2019.

[23] A. Ström, J. Andersson, K. Skagius, and A. Winberg, "Site descriptive modelling during characterization for a geological repository for nuclear waste in Sweden," Applied Geochemistry, vol. 23, no. 7, pp. 1747-1760, 2008.

[24] A. Salama, M. F. el Amin, and S. Y. Sun, "Numerical investigation of high level nuclear waste disposal in deep anisotropic geologic repositories," Progress in Nuclear Energy, vol. 85, no. 11, pp. 747-755, 2015.

[25] F. Dupray, C. Li, and L. Laloui, "THM coupling sensitivity analysis in geological nuclear waste storage," Engineering Geology, vol. 163, no. 8, pp. 113-121, 2013.

[26] R. Jonny, L. G. Zheng, and F. Chen, "Modeling of coupled thermo-hydro-mechanical processes with links to geochemistry associated with bentonite-backfilled repository tunnels in clay formations," Rock Mechanics and Rock Engineering, vol. 47, no. 1, pp. 167-186, 2014.

[27] L. G. Zheng, J. Rutqvist, H. Xu, and J. T. Birkholzer, "Coupled THMC models for bentonite in an argillite repository for nuclear waste: illitization and its effect on swelling stress under high temperature," Engineering Geology, vol. 230, no. 11, pp. 118-129, 2017.

[28] W. C. Zhu, C. H. Wei, J. Liu, H. Y. Qu, and D. Elsworth, "A model of coal-gas interaction under variable temperatures," International Journal of Coal Geology, vol. 86, no. 2-3, pp. 213-221, 2011.

[29] Y. Jin, X. Li, M. Y. Zhao, X. Liu, and H. Li, “A mathematical model of fluid flow in tight porous media based on fractal 
assumptions," International Journal of Heat and Mass Transfer, vol. 108, no. 3, pp. 1078-1088, 2017.

[30] S. Harpalani and A. Schraufnagel, "Measurement of parameters impacting methane recovery from coal seams," International Journal of Coal Geology, vol. 8, no. 4, pp. 369-384, 1990.

[31] C. Wang, J. Feng, J. Liu, M. Wei, C. Wang, and B. Gong, "Direct observation of coal-gas interactions under thermal and mechanical loadings," International Journal of Coal Geology, vol. 131, no. 9, pp. 274-287, 2014.

[32] T. Teng, Y. X. Zhao, F. Gao, J. G. Wang, and W. Wang, "A fully coupled thermo-hydro-mechanical model for heat and gas transfer in thermal stimulation enhanced coal seam gas recovery," International Journal of Heat and Mass Transfer, vol. 125, no. 10, pp. 866-875, 2018.

[33] Z. W. Chen, J. S. Liu, D. Elsworth, L. D. Connell, and Z. Pan, "Impact of $\mathrm{CO}_{2}$ injection and differential deformation on $\mathrm{CO}_{2}$ injectivity under in-situ stress conditions," International Journal of Coal Geology, vol. 81, no. 2, pp. 97-108, 2010.

[34] Y. Xue, J. Liu, P. G. Ranjith, X. Liang, and S. Wang, "Investigation of the influence of gas fracturing on fracturing characteristics of coal mass and gas extraction efficiency based on a multi-physical field model," Journal of Petroleum Science and Engineering, vol. 206, no. 109018, pp. 1-19, 2021.

[35] T. Q. Xia, F. B. Zhou, J. S. Liu, J. Kang, and F. Gao, “A fully coupled hydro-thermo-mechanical model for the spontaneous combustion of underground coal seams," Fuel, vol. 125, no. 6, pp. 106-115, 2014.

[36] Y. Xue, T. Teng, F. Dang, Z. Ma, S. Wang, and H. Xue, "Productivity analysis of fractured wells in reservoir of hydrogen and carbon based on dual-porosity medium model," International Journal of Hydrogen Energy, vol. 45, no. 39, pp. 20240-20249, 2020. 